University of Wollongong

Research Online

Faculty of Engineering - Papers (Archive)

Faculty of Engineering and Information

Sciences

2010

\title{
Subsynchronous torsional interaction behaviour of wind turbine-generator unit connected to an HVDC system
}

Yin Chin Choo

University of Wollongong

Ashish Agalgaonkar

University of Wollongong, ashish@uow.edu.au

Kashem Muttaqi

University of Wollongong, kashem@uow.edu.au

Sarath Perera

University of Wollongong, sarath@uow.edu.au

M. Negnevitsky

University of Tasmania

Follow this and additional works at: https://ro.uow.edu.au/engpapers

Part of the Engineering Commons

https://ro.uow.edu.au/engpapers/5523

\section{Recommended Citation}

Choo, Yin Chin; Agalgaonkar, Ashish; Muttaqi, Kashem; Perera, Sarath; and Negnevitsky, M.:

Subsynchronous torsional interaction behaviour of wind turbine-generator unit connected to an HVDC system 2010.

https://ro.uow.edu.au/engpapers/5523

Research Online is the open access institutional repository for the University of Wollongong. For further information contact the UOW Library: research-pubs@uow.edu.au 


\title{
Subsynchronous Torsional Interaction Behaviour of Wind Turbine-Generator Unit Connected to an HVDC System
}

\author{
Yin Chin Choo*, A. P. Agalgaonkar*, K. M. Muttaqi*, S. Perera* and M. Negnevitsky ${ }^{\dagger}$ \\ ${ }^{*}$ Integral Energy Power Quality and Reliability Centre, \\ School of Electrical, Computer and Telecommunications Engineering, \\ University of Wollongong, NSW 2522, AUSTRALIA \\ Email: ycc260@uow.edu.au, ashish@uow.edu.au,kashem@uow.edu.au, sarath@uow.edu.au \\ ${ }^{\dagger}$ Centre for Renewable Energy and Power Systems, \\ School of Engineering, University of Tasmania, Hobart 7005, AUSTRALIA \\ Email: Michael.Negnevitsky@utas.edu.au
}

\begin{abstract}
Utilisation of wind energy to generate electricity has attracted considerable attention worldwide, and is rapidlygrowing. The integration of large wind farms with high voltage direct current (HVDC) transmission network could be one of the preferred options for supplying bulk power over a long distance. Since HVDC rectifier stations with constant current control may introduce negative damping on the nearby generating units, it is important to identify the torsional interaction characteristics between turbine-generator units and the HVDC systems over a frequency range of interest. However, very little related information exists in regard to wind turbine-generators. This paper presents the electromagnetic transient time domain analysis to investigate the possible subsynchronous torsional interaction (SSTI) phenomenon of fixed-speed (induction machine based) wind turbine-generator (WTG) unit interconnected to a CIGRE first HVDC benchmark system. Electrical disturbances, such as three-phase short circuit fault at the inverter station and DC power flow change are simulated to examine the possible dynamic interactions of the WTG unit. Simulation studies are conducted using PSCAD ${ }^{\circledR} /$ EMTDC $^{\circledR}$.
\end{abstract}

\section{INTRODUCTION}

The grid integration of wind resources is rapidly-growing all over the world due to its environmental benefits [1], [2]. The wind generation capacity has profilerated from merely 5 GW in early 1990s to more than $50 \mathrm{GW}$ today [3], [4]. This development inexorably integrates wind turbine generators (WTGs) into the electrical network in a large scale, thereby posing numerous challenges to all parties concerned.

WTG units exhibit different characteristics compared to steam and hydro units, which typically feature high turbine inertia and low shaft stiffness between the turbine and generator rotor [2], [5]. These characteristics result in a lightly damped, low frequency torsional shaft mode oscillations, wherein the turbine (hub and blades) swings coherently against the generator [6]. It is also demonstrated in [6] that the soft shaft mode can be excited by random wind variations, which results in large oscillatory fluctuations in the shaft torques and the electrical power. Prospective interactions of WTG units connected to a series-compensated line and an high voltage direct current
(HVDC) link are discussed in [7]. The performance issues related to the dynamic characteristics of both conventional induction generators and doubly-fed induction machine based wind turbines are also discussed. However, subsynchronous torsional interaction (SSTI) between the wind farm and the HVDC system was not investigated thoroughly.

The undesirable interactions between the HVDC terminal and the $11.5 \mathrm{~Hz}$ torsional mode of an electrically-close turbinegenerator unit were noted during the field tests conducted at Square Butte in North Dakota [8]. Subsequently, it was revealed that the HVDC rectifier stations with constant current control may introduce negative damping on the nearby generating units [8]. A current-controlled voltage-source converter, located electrically close to the generator may also introduce negative damping in the certain frequency range and proper design of current controller may nullify the possibility of negative damping [9]. SSTI characteristics can possibly be observed when a WTG unit is connected in the close vicinity of the HVDC system. ABB has conducted comprehensive system studies for integrating large wind farms in the American electricity network, especially in the close vicinity of HVDC [10]. However, little information exists in the literature in regard to the SSTI behaviour of an individual WTG unit connected to HVDC system. The objective of this paper is to model a WTG system, including the dynamics of the blade and shaft systems, connected to an HVDC system for SSTI analysis.

The paper is structured as follows: Section II outlines the fixed-speed induction machine based WTG modelling, which includes blade dynamics, shaft model and induction generator model. Section III demonstrates the perturbation analysis for a WTG unit for an investigation of the possible dynamic interactions. Section IV briefly describes the SSTI phenomenon when a turbine-generator is connected in the vicinity of an HVDC system. A study system involving a WTG unit interconnected to a CIGRE first HVDC benchmark system is presented in Section V. The time domain simulation studies 
using PSCAD ${ }^{\circledR} /$ EMTDC $^{\complement}$ and frequency spectrum analysis are used to investigate the SSTI behaviour of WTG unit for electrical disturbances on HVDC system and the results are presented in Section VI. Section VII concludes the paper.

\section{Wind TURBInE-GENERATOR MODEL}

The modelling aspects related to wind energy capturing mechanism, torsional shaft system, the induction machine and the electrical network are presented in this section. The MOD2 type WTG model is used for the wind system representation in $\mathrm{PSCAD}^{\circledR} / \mathrm{EMTDC}^{\circledR}$.

\section{A. Blade Dynamics}

The power extraction from wind and associated mechanical torque can be mathematically represented as follows [11], [12]:

$$
\begin{aligned}
P & =\frac{1}{2} \rho A v_{w}^{3} C_{p}(\lambda, \beta) \\
T & =\frac{P}{\omega_{m}}
\end{aligned}
$$

where $P=$ wind power in watts, $\rho=$ air density in $\mathrm{kg} / \mathrm{m}^{3}, A=$ area swept by wind blade in $\mathrm{m}^{2}, v_{w}=$ wind speed in $\mathrm{m} / \mathrm{s}, \lambda=$ tip speed ratio, $\beta=$ blade pitch angle in degrees, $C_{p}=$ power coefficient, $T=$ torque in $\mathrm{Nm}, \omega_{m}=$ turbine mechanical speed in $\mathrm{rad} / \mathrm{s}$.

The power coefficient $C_{p}$ is a function of both $\lambda$ and $\beta$, and is generally nonlinear. The approximate expressions for nonlinear blade dynamics are as follows [12]:

$$
\begin{aligned}
\omega_{h} & =\frac{\omega_{m}}{G R} \\
\lambda & =\frac{2.237 v_{w}}{\omega_{h}} \\
C_{p} & =\frac{1}{2}\left(\lambda-0.022 \beta^{2}-5.6\right) e^{-0.17 \lambda}
\end{aligned}
$$

where $\omega_{h}$ is a hub speed in $\mathrm{m} / \mathrm{s}$ and GR is a gear ratio.

A power coefficient versus tip speed ratio $\left(C_{p}-\lambda\right)$ characteristic curve for a typical MOD-2 type WTG is shown in Fig. 1 for a wind speed of $15 \mathrm{~m} / \mathrm{s}$ with different blade pitch angles.

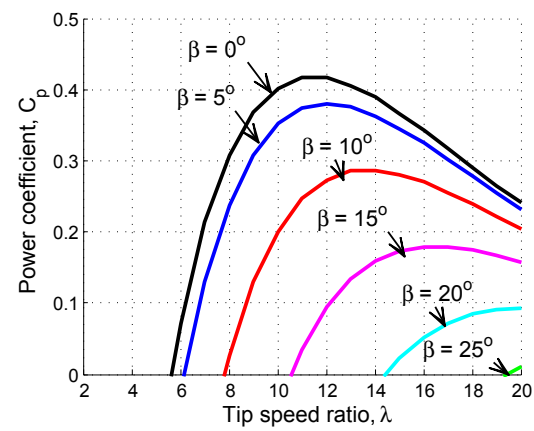

Fig. 1. Power coefficient vs tip speed ratio characteristic of a MOD-2 type WTG for different pitch angles

\section{B. Shaft Model}

The mechanical shaft system of a WTG unit generally comprises of a turbine, low-speed shaft, gearbox, high-speed shaft and generator rotor. It can be represented as a massspring-damper system as shown in Fig. 2 [2], [6]. The inertia of the blades are represented as a lumped inertia. The inertia of the high speed shaft aggregates the individual inertias of both gearbox and generator, assuming the high speed shaft to be rigid. The inertia of the low speed shaft is shared between hub and gearbox [6].

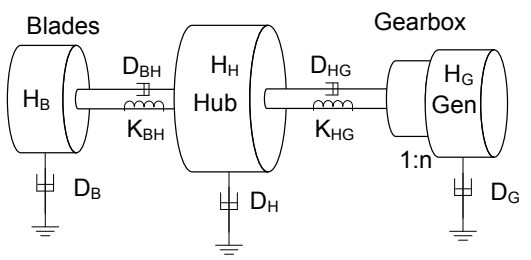

Fig. 2. Mass-spring-damper shaft model of WTG unit

The mechanical shaft system of a WTG unit is represented based on a mass-sping-damper system as follows [6], [13]:

$$
\begin{aligned}
2 H_{i} s \Delta \omega_{i} & =\Delta T_{i}+\Delta T_{i j}-\Delta T_{j k}-D_{i} \Delta \omega_{i} \\
\Delta T_{i j} & =K_{i j}\left(\Delta \theta_{i}-\Delta \theta_{j}\right)+D_{i j}\left(\Delta \omega_{i}-\Delta \omega_{j}\right)
\end{aligned}
$$

where $s$ is the Laplace operator, $\omega$ and $\theta$ are the rotor speed and angle respectively, $H_{i}$ is the inertia constant of mass $i, T_{i}$ is the external torque applied on mass $i, D_{i}$ is the damping coefficient of mass $i, T_{i j}, K_{i j}$ and $D_{i j}$ are the torsional torque, spring constant and damping coefficient between masses $i$ and $j$ respectively. A WTG shaft model with typical values of inertia constants and spring constants, in accordance with Fig. 2 is as shown in Table I. This tabulated data is used for SSTI analysis presented in this paper. Typically, torsional frequencies of oscillation $\left(f_{n}\right)$ for the WTG shaft model can be calculated as follows [14]:

$$
f_{n}=\frac{1}{2 \pi} \sqrt{-\frac{b}{2} \pm \frac{\sqrt{b^{2}-4 c}}{2}}
$$

where

$$
\begin{aligned}
b & =-\left[K_{B H}\left(\frac{1}{2 H_{B}}+\frac{1}{2 H_{H}}\right)+K_{H G}\left(\frac{1}{2 H_{H}}+\frac{1}{2 H_{G}}\right)\right] \\
c & =K_{B H} K_{H G} \frac{\left(H_{B}+H_{H}+H_{G}\right)}{2^{2} H_{B} H_{H} H_{G}}
\end{aligned}
$$

and subscripts $G, H$ and $B$ in the expressions for ' $b$ ' and ' $c$ ' refer to generator, hub and blade masses respectively. Accordingly, it is observed that the torsional frequencies for the WTG shaft system under consideration are $0.6086 \mathrm{~Hz}$ and $4.9818 \mathrm{~Hz}$ respectively.

TABLE I

ShaFt MOdEL OF WTG UNIT [6]

\begin{tabular}{|c|c|c|c|c|}
\hline $\begin{array}{c}H_{B} \\
(\mathrm{~s})\end{array}$ & $\begin{array}{c}H_{H} \\
(\mathrm{~s})\end{array}$ & $\begin{array}{c}H_{G} \\
(\mathrm{~s})\end{array}$ & $\begin{array}{c}K_{B H} \\
(\mathrm{pu} / \mathrm{el} . \mathrm{rad})\end{array}$ & $\begin{array}{c}K_{H G} \\
(\mathrm{pu} / \mathrm{el} . \mathrm{rad})\end{array}$ \\
\hline \hline 9.1150 & 0.4764 & 1.0455 & 2.7410 & 0.0904 \\
\hline
\end{tabular}




\section{Induction Generator Model}

A fixed-speed induction machine of fourth order is used to represent the WTG unit, and its voltage and current relationship in the synchronously-rotating reference frame can be expressed as [15]:

$$
v^{e}=Z_{i m} i^{e}
$$

where $v^{e}=\left[\begin{array}{llll}v_{q s}^{e} & v_{d s}^{e} & v_{q r}^{\prime e} & v_{d r}^{\prime e}\end{array}\right]^{-1}, i^{e}=\left[\begin{array}{llll}i_{q s}^{e} & i_{d s}^{e} & i_{q r}^{\prime e} & i_{d r}^{\prime e}\end{array}\right]^{-1}$; subscripts ' $s$ ' and ' $r$ ' represent the stator and rotor side variables respectively, while superscript ' $e$ ' refers to the transformation of rotor side variables into the stator side using the rotor-to-stator turns ratio. $Z_{i m}$ is the induction machine internal impedance matrix.

\section{Perturbation Analysis For A WTG Unit}

The perturbation analysis is conducted to examine the WTG response at different frequencies. The grid side voltage signal is perturbed at different modulated frequencies as shown in Fig. 3. It can be expressed mathematically as follows:

$$
v_{a c}=\left[\omega_{b}+m \sin \left(\omega_{m} t\right)\right] V_{p} \cos \left(\omega_{b} t\right)
$$

where $\omega_{b}$ is the base frequency in $\mathrm{rad} / \mathrm{s}, m$ is the magnitude of the speed deviation, $\omega_{m}$ is the frequency of oscillation of the rotor speed in rad/s, $t$ is the time and $V_{p}$ is the peak voltage.

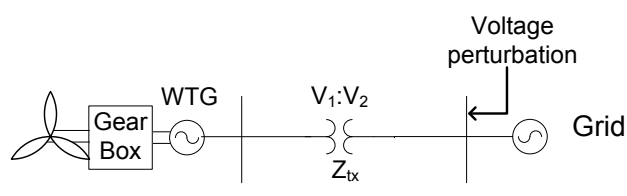

Fig. 3. AC voltage perturbation onto WTG unit

A typical time response of the bus voltage for a modulated frequency $f_{m}$ is as shown in Fig. 4(a). The corresponding representative frequency spectrum of the $\mathrm{AC}$ voltage is shown in Fig. 4(b). It can be seen that the AC voltage oscillates at fundamental $\left(f_{\text {fund }}\right)$, sub- $\left(f_{\text {sub }}\right)$ and super- $\left(f_{\text {super }}\right)$ synchronous frequencies as a consequence of the frequency modulation.

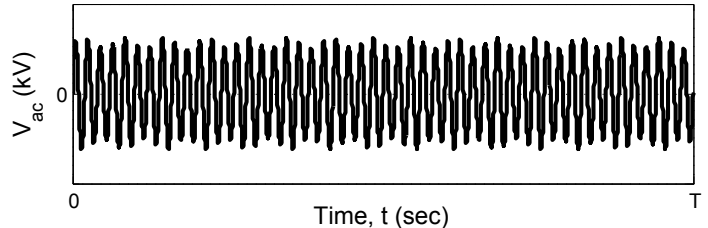

(a)

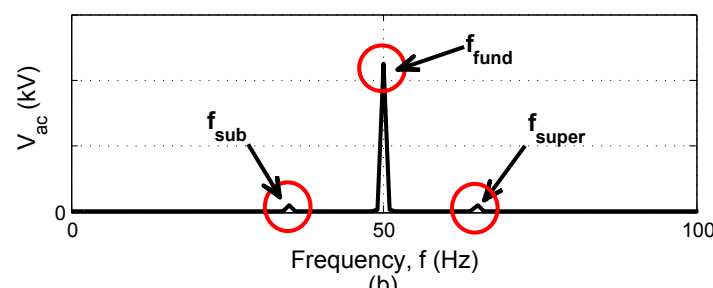

(b)

Fig. 4. (a) Time response and (b) frequency spectrum of AC voltage at a modulated frequency, $f_{m}$ of $15 \mathrm{~Hz}$

It is also envisages that the voltage perturbation at different modulated frequencies may instigate torsional modes of a
WTG unit. The possible dynamic interaction of the WTG unit can be investigated by examining the resulting deviation in blade-hub and hub-generator torques (mechanical torques) of the WTG unit. It may very well depict the WTG response under network disturbances. The simulation results for frequency spectrum analysis of a typical WTG unit are presented in Section VI-A.

\section{SUbSYNCHRONOUS TORSIONAL INTERACTION FOR A MACHine CONNECTEd TO HVDC SySTEM}

SSTI phenomenon for the WTG connected to an HVDC system is elaborated in this section with the assumptions that the generator is directly connected to the HVDC system and the commutating voltage and phase angle at the rectifier station are in accordance with those at the generator internal bus [16].

The machine side AC voltage is oscillating sinusoidally at different frequency components, namely fundamental frequency $f_{b}$, subsynchronous frequency $f_{b}-f_{m}$ and supersynchronous frequency $f_{b}+f_{m}$ as a consequence of torsional oscillations. It can be also looked at as an amplitude and phase modulation of $\mathrm{AC}$ voltage. This results in current oscillations over the HVDC link depending on the effective impedance of the HVDC system [16]. The subsynchronous and supersynchronous frequency components of the $\mathrm{AC}$ current are subsequently induced in the $\mathrm{AC}$ system and hence it is apparent that the electromagnetic torque consists of sub- and super- synchronous frequency components. Typically, negative damping torque results from the subsynchronous frequency currents whilst positive damping torque is provided by the supersynchonous frequency currents [16].

The HVDC system can be represented in terms of a T-model as shown in Fig. 5. An aggregated wind system, including the wind energy capturing mechanism and the torsional shaft system, has been connected to the HVDC system in parallel to the connection of an infinite bus and an $\mathrm{AC}$ filter at the rectifier station as seen in Fig. 5. The constant current (CC) controller is normally installed at the rectifier station with a phase-locked loop (PLL) to ensure a stable system operation. The system equations to depict the operation of the HVDC system including the rectifier side CC controller are as follows [13], [17]:

$$
\begin{aligned}
s I_{d r} & =\frac{V_{d r}-R_{d} I_{d r}-V_{d m}}{L_{d}} \\
s I_{d i} & =\frac{V_{d m}-R_{d} I_{d i}-V_{d i}}{L_{d}} \\
s V_{d m} & =\frac{I_{d r}-I_{d i}}{C_{d}} \\
\alpha & =\left(K_{p}+\frac{K_{i}}{s}\right)\left(I_{o r d}-I_{d r}\right)+\alpha_{P L L}
\end{aligned}
$$

where $I_{d}$ is the DC current, $V_{d}$ is the DC voltage, $V_{d m}$ is the DC voltage on the dc line, $R_{d}, L_{d}$ and $C_{d}$ are the dc line resistance, inductance and capacitance respectively, $\alpha$ is the rectifier firing angle, $K_{p}$ and $K_{i}$ are the proportional and integral gains, $I_{o r d}$ is the reference current and $\alpha_{P L L}$ is the phase lag resulting from PLL. The subscripts $r$ and $i$ 
represent rectifier and inverter side variables respectively. The characteristics of the CC controller and PLL are illustrated in Fig. 6. Fig. 6 shows that the phase angle of the rectifier side AC voltage $\theta_{\text {Eacr }}$ has an effect on the firing angle $\alpha$ with equidistant pulse control. PLL is associated to the controller to synchronise firing angle to the AC voltage [16].

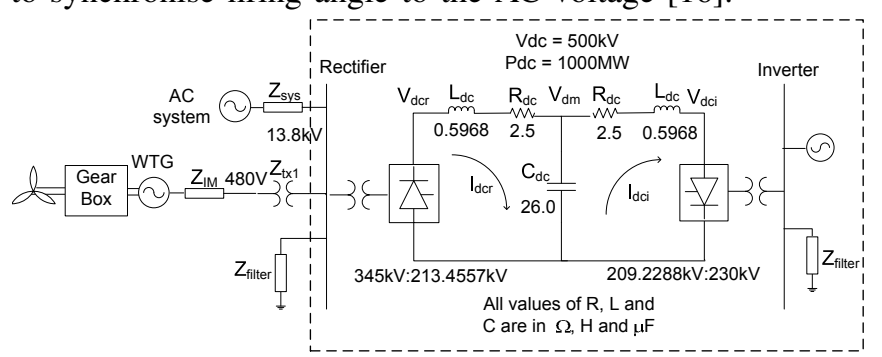

Fig. 5. PSCAD ${ }^{\circledR} /$ EMTDC $^{\circledR}$ simulated WTG unit connected to an HVDC system

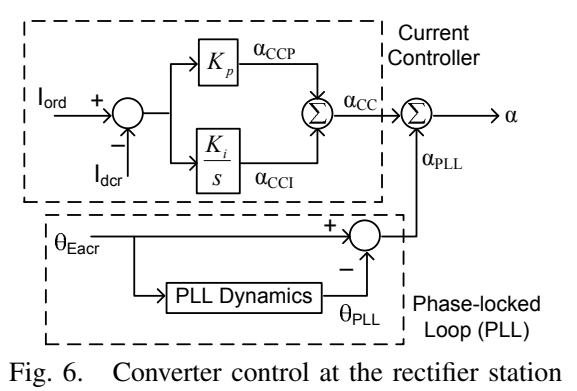

\section{STUdy System}

A WTG unit of 1 MVA capacity with a rated voltage of $480 \mathrm{~V}$ is directly connected to the HVDC system as shown in Fig. 5. The time domain simulation studies are conducted in PSCAD $^{\circledR} /$ EMTDC $^{\circledR}$ to examine SSTI behaviour of a WTG unit for voltage perturbation and network disturbances. The data for the WTG unit is as provided in Table II. The collector system, rated at a voltage of $13.8 \mathrm{kV}$, connects the WTG unit and a $345 \mathrm{kV}$ AC system grid through a 13.8/345 kV transformer. The WTG unit has a blade pitch angle controller of proportional-integral (PI) type, as seen in Fig. 7. In case of a high wind speed condition, the blade pitch angle will be activated and is adjusted to ensure a delivery of the rated power. The pitch angle is varied utmost at the rate of $3^{\circ}-10^{\circ}$ per second determined by the capacity of the wind turbine [3].

The simulation studies are carried out using fixed-speed induction machine based WTG. To operate the induction machine within the range of 0.98-0.99 lagging power factor, supplementary reactive support is required [4], [7]. A local capacitor bank is usually connected at the machine terminal and the rating of the bank is selected to give unity power factor at rated conditions [18]. In this study, it is assumed that the reactive power requirement of the machine has been met by the grid.

The HVDC system is represented by the CIGRE first HVDC benchmark model, with the monopolar DC link rated at 500 $\mathrm{kV}$ and $1000 \mathrm{MW}$ [19]. It is considered that the HVDC system operates at normal conditions, i.e. the rectifier operates at constant current (CC) control mode whilst the inverter operates at constant extinction angle (CEA) control mode.

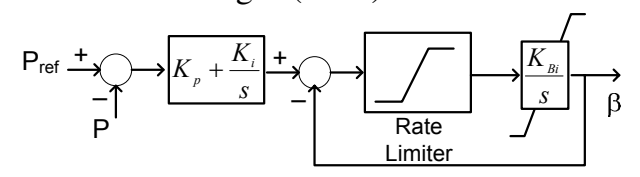

Fig. 7. Blade Pitch Angle Controller

TABLE II

TABLE UNIT PARAMETERS
\begin{tabular}{c|c}
\hline \multicolumn{2}{c}{ WTG } \\
\hline \hline System quantities & Values \\
\hline \hline Rated speed of machine output & $314.1593 \mathrm{rad} / \mathrm{s}$ \\
\hline Wind speed, $v_{w}$ & $15 \mathrm{~m} / \mathrm{s}$ \\
\hline Gear Ratio, $G R$ & 55 \\
\hline Rotor blade radius, $R$ & $20.0 \mathrm{~m}$ \\
\hline Rotor blade swept area, $A$ & $1256.6 \mathrm{~m}^{2}$ \\
\hline Number of poles, $p$ & 6 \\
\hline Gear box efficiency, $G_{e f f}$ & $97 \%$ \\
\hline Machine rated MVA, $G_{M V A}$ & $1.0 \mathrm{MVA}$ \\
\hline Initial pitch angle, $\beta$ & $0^{\circ}$ \\
\hline Air density, $\rho$ & $1.229 \mathrm{~kg} / \mathrm{m}^{3}$ \\
\hline
\end{tabular}

\section{Vi. Simulation Results}

Sustained torsional oscillations could be resulted if the complement of the system resonance frequency is close to the mechanical torsional mode frequency and that the combined electromechanical system lacks in system damping [20]. The main focus of the paper is to investigate the effect of fastacting control loop associated with the current controller at the rectifier station, which could possibly excite torsional oscillations on the nearby generator. PSCAD ${ }^{\circledR} /$ EMTDC $^{\complement}$ simulated model is used to investigate the SSTI interactions of a WTG unit connected to HVDC system.

Simulated line fault on the HVDC system and sinusoidal modulation of the HVDC terminal at the torsional resonant frequency can excite the torsional modes of shaft oscillation [21]. Hence, different case scenarios with the application of the disturbances on the HVDC side, such as three-phase to ground fault at the inverter station and $25 \%$ decrement in the rated DC power flow are considered for SSTI investigation on a WTG unit by conducting time domain simulation studies.

\section{A. Frequency Spectrum Analysis for a WTG unit}

Perturbation analysis is conducted to investigate the oscillatory response of a WTG unit for different frequency injections. The grid side voltage is perturbed to depict network disturbances. The resulting dynamic interactions in blade-hub and hub-generator torques (mechanical torques) of the WTG unit are examined for an injection of different modulated frequency, $f_{m}$. The PSCAD ${ }^{\circledR} /$ EMTDC $^{\circledR}$ simulated circuit for voltage perturbation is shown in Fig. 8.

The terminal voltage as shown in Fig. 8 is modulated at 5 $\mathrm{Hz}$ and $10 \mathrm{~Hz}$. The corresponding time domain and frequency domain responses of blade-hub and hub-generator torques, as well as the machine speed are illustrated in Figs. 9, 10 and 11 respectively. The responses of the WTG unit without any frequency modulation are also presented for comparative analysis. 


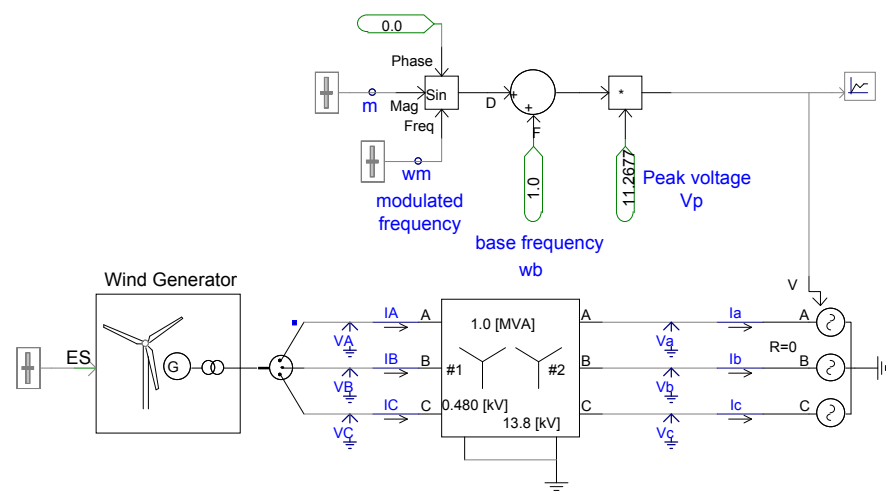

Fig. 8. PSCAD $^{\circledR} /$ EMTDC $^{\circledR}$ simulated test system for perturbation analysis

It is seen in Fig. 9(a) that the blade-hub torque response at a modulated frequency of $10 \mathrm{~Hz}$ does not change appreciably as compared to the torque response without any modulation. Fig. 9(b) illustrates that the torsional mode (with a torsional frequency $f_{n}=4.98 \mathrm{~Hz}$ ) will be excited for a modulated frequency of $10 \mathrm{~Hz}$, but it is of very small value of 0.03 p.u. However, when the terminal voltage is modulated at $5 \mathrm{~Hz}$, growing oscillations will be evidently seen as shown in Fig. 9(c). Fig. 9(d) demonstrates that the torsional mode will be excited when the voltage is modulated at $5 \mathrm{~Hz}$, i.e. close to the torsional mode of the WTG unit. It is observed that the blade-hub torque experience oscillatory response of 0.24 p.u. at $4.98 \mathrm{~Hz}$.

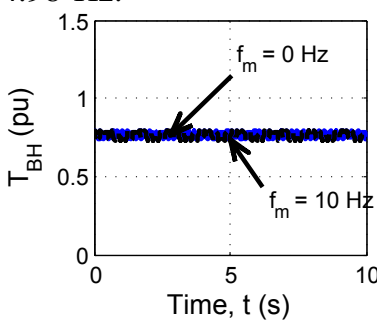

(a)

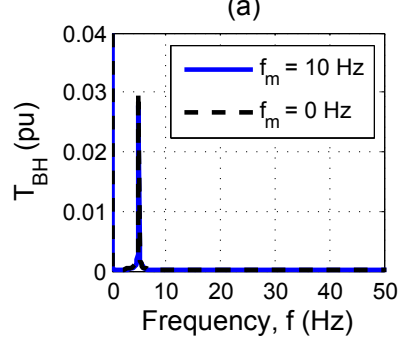

Fig. 9. Time response and frequency spectrum of blade-hub torque at a

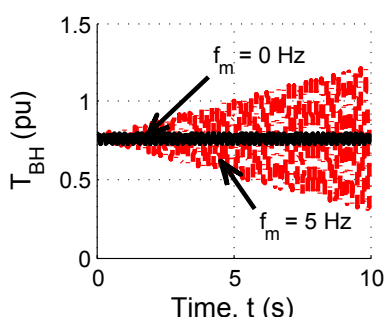

(c)

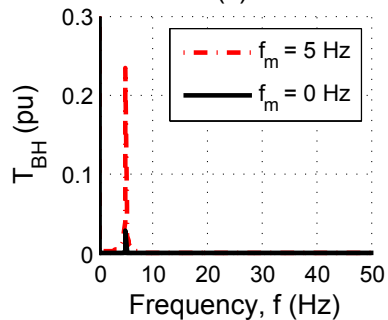

Fig. 9. Time response and frequency spectrum of blade-hub torque at a modulated frequency

Similar time domain and frequency domain responses are observed for a hub-generator torque as demonstrated in Fig. 10. The growing oscillations in the hub-generator torque can be predominantly seen for a modulated frequency of $5 \mathrm{~Hz}$ as shown in Fig. 10(c), whilst the hub-generator torque settles down for a modulated frequency of $10 \mathrm{~Hz}$ as shown in Fig. 10(a). It can be evidently seen in Fig. 10(b) and 10(d) that the torsional mode oscillation at $10 \mathrm{~Hz}$ is of very small value (i.e. 0.00098 p.u.), compared to the one at a modulated frequency of $5 \mathrm{~Hz}$ (i.e. 0.0095 p.u.).
The machine speed oscillates at a larger value when the network side voltage is modulated at a frequency close to the torsional mode of the WTG unit. Accordingly, it can be seen in 11(a) and (c) that the speed deviation at a modulated frequency of $5 \mathrm{~Hz}$ is of larger magnitude as that of the one at a modulated frequency of $10 \mathrm{~Hz}$. The torsional mode, however, has insignificant contribution to the rotor speed deviation as seen in Figs. 11(b) and (d).

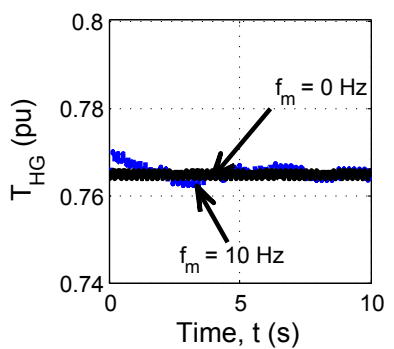

(a)

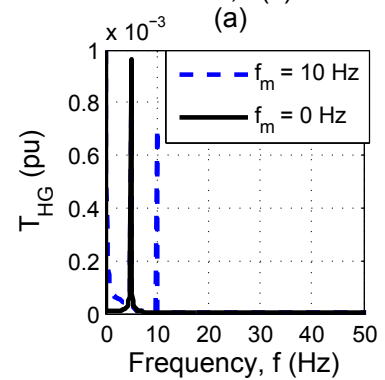

(b)

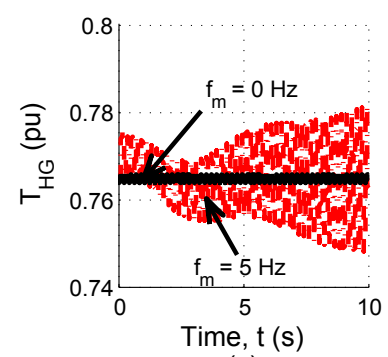

(c)

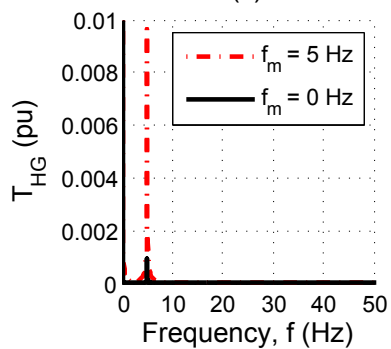

(d)
Fig. 10. Time response and frequency spectrum of hub-generator torque at a modulated frequency
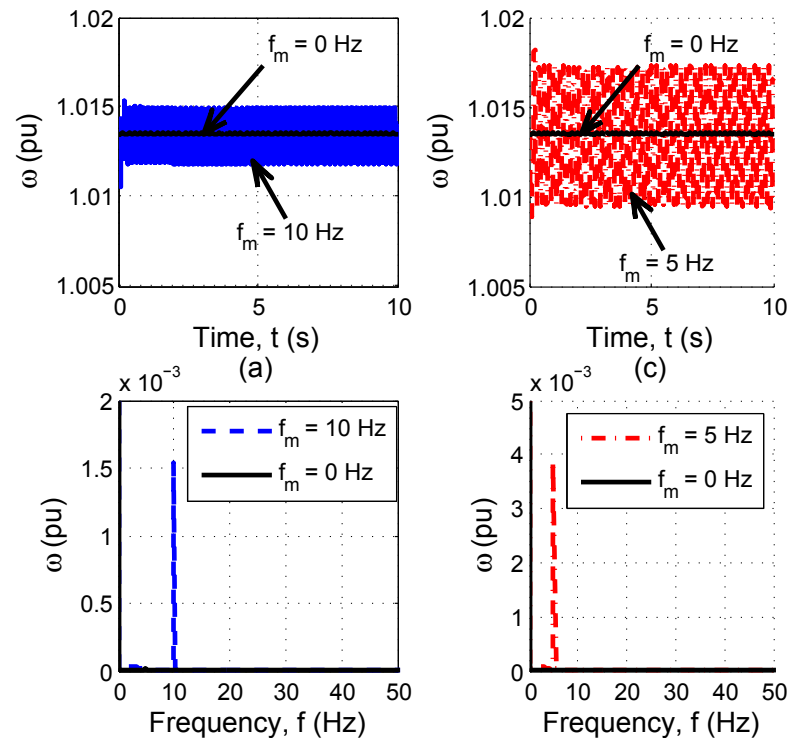

(b)

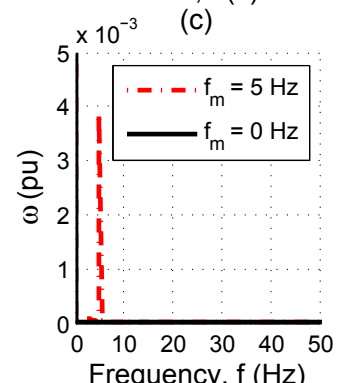

(d)

Fig. 11. Time response and frequency spectrum of machine speed at a modulated frequency

\section{B. WTG Response to Network Disturbances}

Two case scenarios are now considered to investigate the SSTI behaviour of the WTG unit when connected in the close vicinity of HVDC system, i.e. a three-phase to ground fault at inverter station and a DC power flow reduction. 
1) Three-phase to ground fault at the inverter station: The interaction behaviour of the WTG unit of 1 MVA capacity has been examined by applying a three-phase to ground fault of 5 cycles on the inverter station at $t=5 \mathrm{~s}$. The time domain simulation plot and the frequency spectrum for the blade-hub torsional torque $\left(T_{B H}\right)$ and the hub-generator torsional torque $\left(T_{H G}\right)$ of a WTG unit are shown in Figs. 12 - 15 for a threephase to ground fault on the inverter side.

Figs. 12 and 13 show the corresponding time domain responses of the blade-hub and hub-generator torques with reference to the inverter side fault. Figs. 12(a) and 13(a) show the time domain responses in the time range of $0-100 \mathrm{~s}$ whilst Figs. 12(b) and 13(b) give a better illustration on the responses for a shortened time frame of $90 \mathrm{~s} \leq t \leq 100 \mathrm{~s}$. The oscillatory transient responses at $5 \mathrm{~s}$ as seen in Figs. 12(a) and 13(a) are due to the application of the three-phase to ground fault. The transient responses subside to steady-state as soon as the fault is cleared after $0.1 \mathrm{~s}$. The oscillatory response of the blade-hub torque is of larger value (with a torque deviation of 0.07 p.u.) as seen in Fig. 12(b) compared to the hub-generator torque response in Fig. 13(b) (with a torque deviation of 0.002 p.u.).

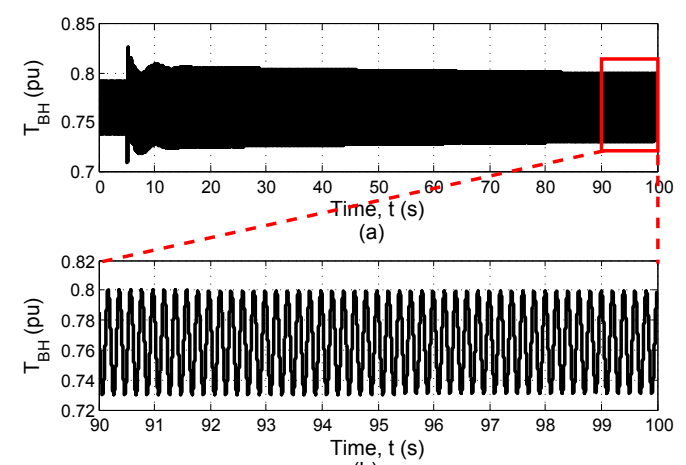

(b)

Fig. 12. Time domain response of blade-hub torque for a three phase fault at the inverter station

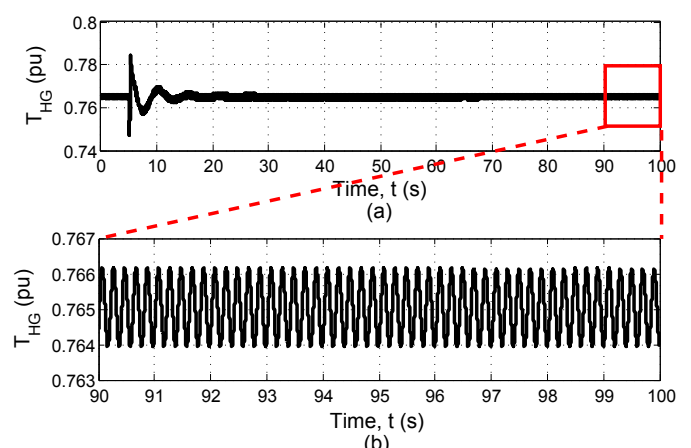

(b)

Fig. 13. Time domain response of hub-generator torque for a three phase fault at the inverter station

It is seen in Figs. 14 and 15 that the oscillatory fluctuations of $4.98 \mathrm{~Hz}$ occur in both blade-hub and hub-generator torques when a three-phase to ground fault is applied at the inverter station. Some of the other low-frequency components of very small magnitude also appear in the blade-hub and hubgenerator torques. Fig. 14 highlights a large oscillatory mode of $4.98 \mathrm{~Hz}$ with the torque deviation of 0.034 p.u. in the blade- hub torque. Fig. 15 demonstrates small oscillatory mode of $4.98 \mathrm{~Hz}$ in the hub-generator torque with a torque deviation of 0.0011 p.u.

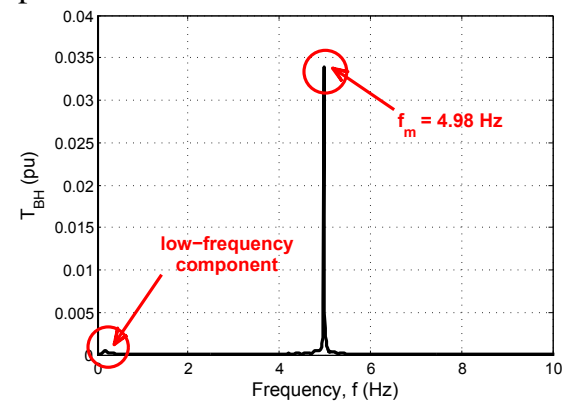

Fig. 14. Frequency spectrum of blade-hub torque for a three phase fault at the inverter station

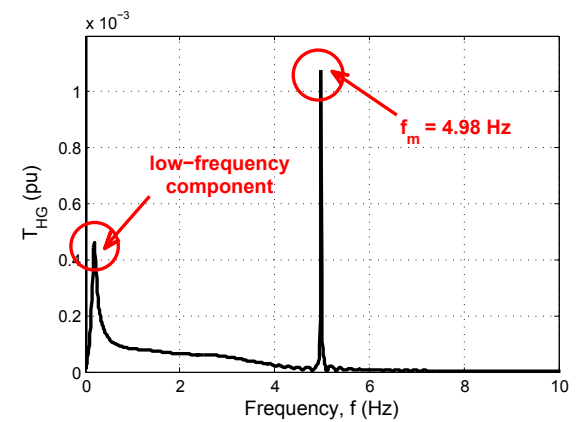

Fig. 15. Frequency spectrum of hub-generator torque for a three phase fault at the inverter station

The time domain responses of the machine speed and the electromagnetic torque output of the WTG unit for an inverter side fault are illustrated in Figs. 16 and 17 respectively. Figs. 16(a) and 17(a) show the entire time domain responses of the machine speed and electromagnetic torque for $0 \mathrm{~s} \leq t \leq$ $100 \mathrm{~s}$, and oscillatory transient responses at $5 \mathrm{~s}$ is resulted from the application of the three-phase to ground fault at the inverter station. It is observed that the machine speed and the electromagnetic torque settle down very quickly after the disturbance at the inverter station. However, sustained oscillations from the disturbances result which can be seen in Figs. 16(b) and 17(b) respectively, in the shortened time range of $90-100 \mathrm{~s}$.
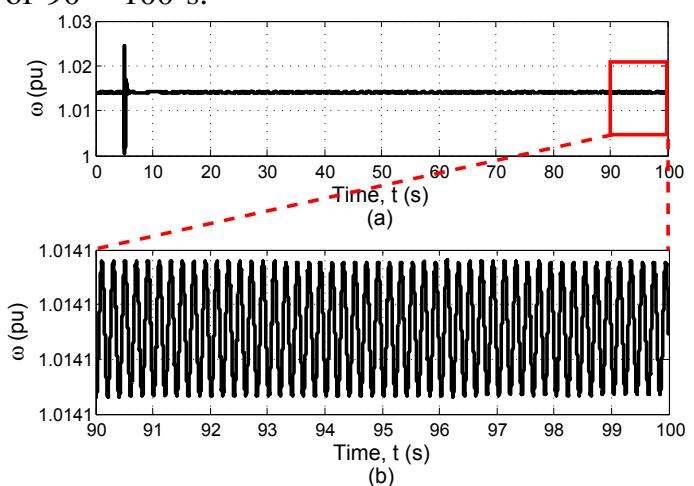

Fig. 16. Time domain response of electrical speed for a three phase fault at the inverter station

2) Change in DC Power Flow: The behaviour of WTG unit is investigated by decreasing the DC power flow by $25 \%$, 
i.e. from $1000 \mathrm{MW}$ to $750 \mathrm{MW}$. The resulting time domain simulation plot and the frequency spectrum of the blade-hub torque $T_{B H}$ and hub-generator torque $T_{H G}$ are depicted in Figs. $18-21$.

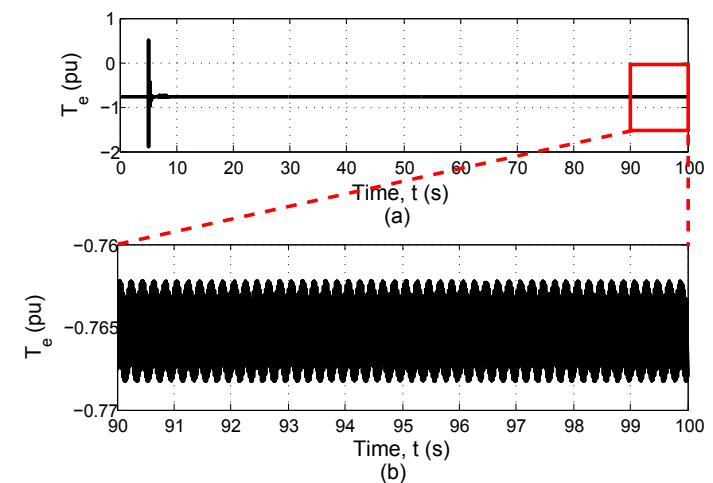

Fig. 17. Time domain response of electromagnetic torque for a three phase fault at the inverter station

Figs. 18 and 19 illustrate the time domain responses of the blade-hub and the hub-generator torques resulting from a DC power flow change at $t=5 \mathrm{~s}$. Figs. 18(a) and 19(a) show the entire time domain responses in the time range of $0-100 \mathrm{~s}$ whereas Figs. 18(b) and 19(b) depict torque responses in the shortened time range of $90 \mathrm{~s} \leq t \leq 100 \mathrm{~s}$. The oscillatory transient responses at $5 \mathrm{~s}$ as seen in Figs. 18(a) and 19(a) are due to the sudden change in DC power flow from $1000 \mathrm{MW}$ to 750 MW. The blade-hub torque deviation as seen in Fig. 18(b) is of larger amplitude ( $\approx 0.0375$ p.u.) compared to the hubgenerator torque deviation, which is of approximately 0.0011 p.u. as depicted in Fig. 19(b). The responses of blade-hub and hub-generator torques settle down after the reduction in the DC power flow, however the sustained oscillatory response can be seen throughout the simulation. The oscillatory time responses of the torsional torques in Figs. 18 and 19 contain numerous low-frequency components resulting from the change in DC power transfer. This is illustrated in Figs. 20 where the blade-hub torque component at $4.98 \mathrm{~Hz}$ dominates other lowfrequency components and have a value of 0.018 p.u. On the other hand, the hub-generator torque has a lower value of 0.000625 p.u. at $4.98 \mathrm{~Hz}$ as shown in Fig. 21.

The time domain response of machine speed is shown in Fig. 22. It can be seen that the electromagnetic torque fluctuation is between -0.7625 p.u. to -0.7675 p.u. in case of an inverter side fault as shown in Fig. 17 while the same is between -0.762 p.u. to -0.767 p.u. for a change in DC power flow as shown in Fig. 23. The transient responses resulted in Figs. 22(a) and 23(a) at $5 \mathrm{~s}$ are due to the sudden DC power flow reduction from $1000 \mathrm{MW}$ to $750 \mathrm{MW}$.

The simulation results emphasise that there could be torsional oscillations in a WTG unit when it is connected in the close-vicinity of an HVDC system. The small frequency components of torsional torques are observed in a WTG unit due to the large turbine inertia, low generator inertia and low shaft stiffness. It is realised that the modelling of the shaft system will play key role in the SSTI analysis. It is also observed that the oversimplification of the shaft model may not adequately represent the torsional dynamics and the simulation results may be erroneous.

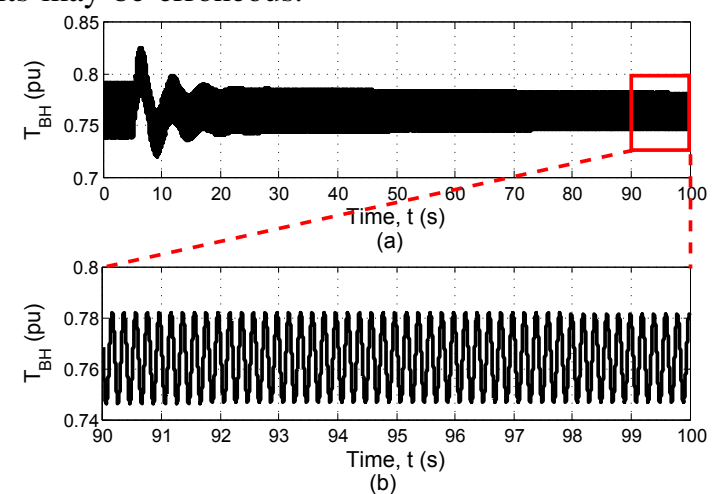

Fig. 18. Time domain response of blade-hub torque for $25 \%$ decrement of DC power transfer

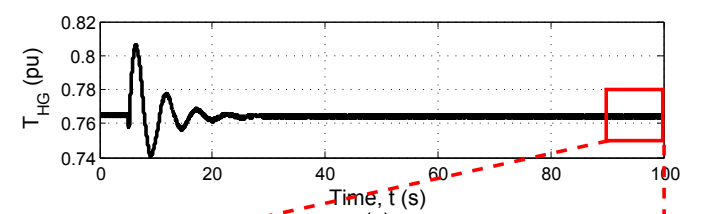

(a)

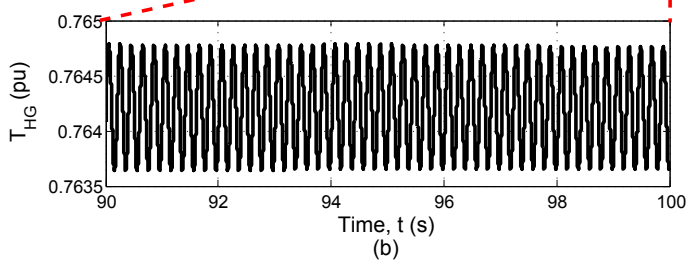

Fig. 19. Time domain response of hub-generator torque for $25 \%$ decrement of DC power transfer

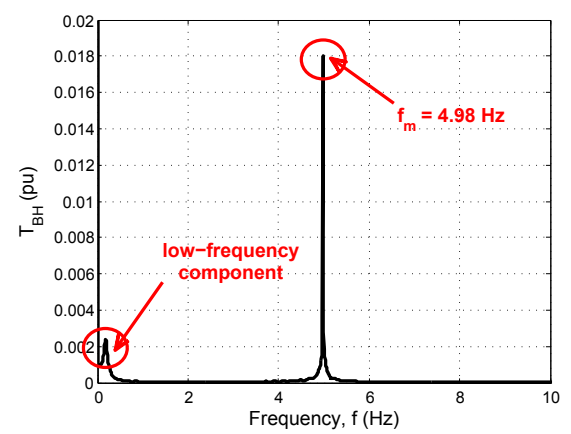

Fig. 20. Frequency spectrum of blade-hub torque for $25 \%$ decrement of DC power transfer

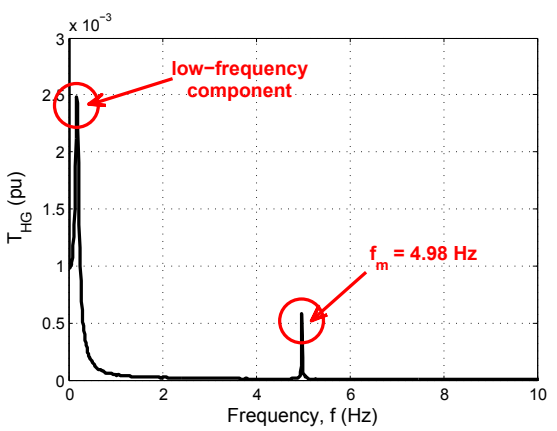

Fig. 21. Frequency spectrum of hub-generator torque for $25 \%$ decrement of DC power transfer 


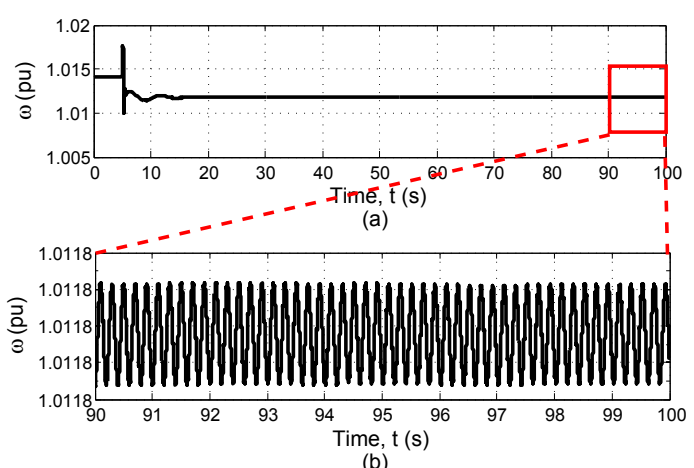

(b)

Fig. 22. Time domain response of electrical speed for $25 \%$ decrement of DC power transfer
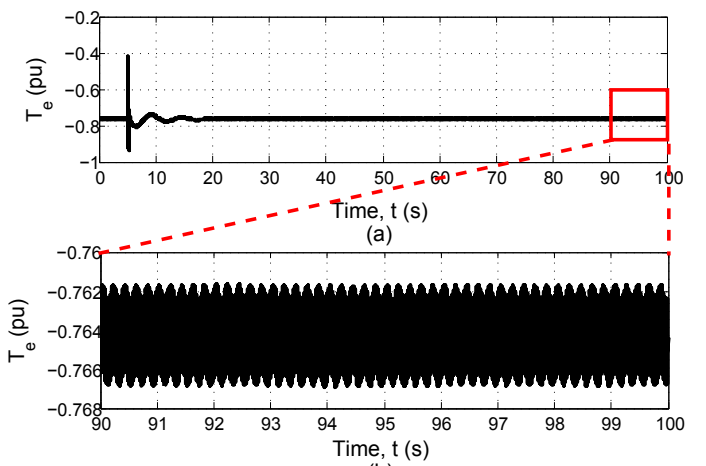

(b)

Fig. 23. Time domain response of electromagnetic torque for $25 \%$ decrement of DC power flow

\section{CONCLUSIONS}

This paper investigates the SSTI behaviour of a fixed-speed induction machine based WTG unit using time domain simulation studies conducted in PSCAD ${ }^{\circledR} /$ EMTDC $^{\circledR}$ environment. The perturbation analysis has been conducted for a WTG unit to analyse the time response and frequency spectrum of different torque components at modulated frequencies. It is observed that there will be growing torque oscillations if the modulated frequency is close to the torsional mode of a WTG unit and the combined electromechanical system lacks damping. The torsional mode will be excited with the significant deviation in the torque components. In order to examine the effect of negative damping being introduced by the rectifier side current control of an HVDC system, the time domain simulation studies are conducted for a WTG unit interconnected to a CIGRE first HVDC benchmark system. The subsynchronous torsional behaviour of a WTG unit has been investigated under two case scenarios highlighting network disturbances i.e. a three-phase to ground fault at the inverter station and change in DC power flow. It is observed that the low-frequency torsional mode will be excited for a WTG unit connected in the close vicinity of an HVDC system. The resulting oscillatory fluctuations in the blade-hub torque of a WTG unit are substantially high in comparison with the one in the hub-generator torque for the specified electrical disturbances. The torsional torques may eventually settle down after a certain time interval, however, the sustained torsional oscillations may result in fatigue damage and reduce the fatigue life of the mechanical shaft system.

\section{ACKNOWLEDGMENT}

This research has been funded by the Australian Research Council (ARC) under ARC Discovery Grant DP0666431 "Optimising Control of Hydroelectric Turbines Subject to Basslink Instability".

\section{REFERENCES}

[1] A. Tabesh and R. Iravani, "Small-signal dynamic model and analysis of a fixed-speed wind farm - a frequency response approach," IEEE Trans. Power Del., vol. 21, no. 2, pp. 778 - 787, Apr. 2006.

[2] S. K. Salman and A. L. J. Teo, "Windmill modeling consideration and factors influencing the stability of a grid-connected wind power based embedded generator," IEEE Trans. Power Syst., vol. 18, no. 2, pp. 793 802, May 2003.

[3] T. Ackermann, Wind Power in Power Systems. John Wiley \& Sons, 2005.

[4] R. K. Varma, S. Auddy, and Y. Semsedini, "Mitigation of subsynchronous resonance in a series-compensated wind farm using FACTS controllers," IEEE Trans. Power Del., vol. 23, no. 3, pp. $1645-1654$, Jul. 2008.

[5] E. N. Hinrichsen and P. J. Nolan, "Dynamics and stability of wind turbine generators," IEEE Trans. Power App. Syst., vol. PAS-101, no. 8, pp. $2640-2648$, Aug. 1982.

[6] O. Wasynczuk, D. T. Man, and J. P. Sullivan, "Dynamic behavior of a class of wind turbine generators during random wind fluctuations," IEEE Trans. Power App. Syst., vol. PAS-100, no. 6, pp. $2837-2845$, Jun. 1981.

[7] P. Pourbeik, R. J. Koessler, D. L. Dickmander, and W. Wong, "Integration of large wind farms into utility grids (part 2 - performance issues)," in Proc. 2003 IEEE Power Eng. Soc. General Meeting.

[8] M. Bahrman, E. V. Larsen, R. J. Piwko, and H. S. Patel, "Experience with HVDC-turbine-generator torsional interaction at square butte," IEEE Trans. Power App. Syst., vol. PAS-99, no. 3, pp. 966 -975, May 1980.

[9] L. Harnefors, "Analysis of subsynchronous torsional interaction with power electronic converters," IEEE Trans. Power Syst., vol. 22, no. 1 pp. $305-313$, Feb. 2007.

[10] ABB experience in the analysis of wind farms and their interconnection to utility grids. [Online]. Available: http://www05.abb.com/global/scot/ scot221.nsf/veritydisplay/952ce63c8e46f738c1256fda003b4d69

[11] S. Heier, Grid Integration of Wind Energy Conversion Systems. John Wiley \& Sons, 1998

[12] P. M. Anderson and A. Bose, "Stability simulation of wind turbine systems," IEEE Trans. Power App. Syst., vol. PAS-102, no. 12, pp. 3791 -3795 , Dec. 1983.

[13] P. Kundur, Power System Stability and Control. McGraw-Hill, 1994.

[14] O. Anaya-Lara, N. Jenkins, J. Ekanayake, P. Cartwright, and M. Hughes., Wind Energy Generation Modelling and Control. John Wiley \& Sons, 2009.

[15] P. C. Krause, O. Wasynczuk, and S. D. Sudhoff, Analysis of Electric Machinery. The Institute of Electrical and Electronics Engineers, Inc., New York, 1995.

[16] K. R. Padiyar, Analysis of Subsynchronous Resonance in Power Systems. Kluwer Academic Publishers, 1999.

[17] Y. C. Choo, A. P. Agalgaonkar, K. M. Muttaqi, S. Perera, and M. Negnevitsky, "Subsynchronous torsional behaviour of a hydraulic turbinegenerator unit connected to a HVDC system," in Proc. Australasian Universities Power Eng. Conf. (AUPEC'08), Sydney, New South Wales, Dec.14-17, 2008.

[18] S. M. Muyeen, M. H. Ali, R. Takahashi, T. Murata, and J. Tamura, "Damping of blade-shaft torsional oscillations of wind turbine generator system," Electric Power Components and Systems, vol. 36, no. 2, pp. 195-211, Feb. 2008.

[19] M. Szechtman, T. Wess, and C. V. Thio, "First benchmark model for HVDC control studies," Electra, no. 135, pp. 54-73, Apr. 1991.

[20] "Proposed terms and definitions for subsynchronous oscillations," IEEE Trans. Power App. Syst., vol. PAS-99, no. 2, pp. 506 -511, Mar. 1980.

[21] K. Mortensen, E. V. Larsen, and R. J. Piwko, "Field tests and analysis of torsional interaction between the coal creek turbine-generators and the CU HVDC system," IEEE Trans. Power App. Syst., vol. PAS-100, no. 1 , pp. $336-344$, Jan. 1981. 